\title{
REVISED The nocebo effect as a source of bias in the assessment
}

\section{of treatment effects [version 2; peer review: 1 approved, 2}

\section{approved with reservations]}

Previously titled: Nocebo as a source of bias in the assessment of treatment effect

\author{
Karolina Wartolowska (iD)
}

Nuffield Department of Primary Care Health Sciences, University of Oxford, Oxford, OX2 6GG, UK

V2 First published: 03 Jan 2019, 8:5

https://doi.org/10.12688/f1000research.17611.1

Latest published: 11 Mar 2019, 8:5

https://doi.org/10.12688/f1000research.17611.2

\section{Open Peer Review}

\begin{tabular}{lccc} 
Approval Status & $? \checkmark ?$ \\
& 1 & 2 & 3 \\
\hline version 2 & & & \\
(revision) & & view & view \\
11 Mar 2019 & & 9 & \\
version 1 & $?$ & $?$ & \\
03 Jan 2019 & view & view & \\
\hline
\end{tabular}

1. Paul Dieppe, University of Exeter, Exeter, UK

2. Przemysław Bąbel ID, Jagiellonian

University, Kraków, Poland

3. Jian Kong, Harvard Medical School,

Charlestown, USA

Any reports and responses or comments on the article can be found at the end of the article. 
Corresponding author: Karolina Wartolowska (karolina.wartolowska@phc.ox.ac.uk)

Author roles: Wartolowska K: Conceptualization, Resources, Software, Writing - Original Draft Preparation, Writing - Review \& Editing Competing interests: No competing interests were disclosed.

Grant information: The author(s) declared that no grants were involved in supporting this work.

Copyright: $\odot 2019$ Wartolowska K. This is an open access article distributed under the terms of the Creative Commons Attribution License, which permits unrestricted use, distribution, and reproduction in any medium, provided the original work is properly cited.

How to cite this article: Wartolowska K. The nocebo effect as a source of bias in the assessment of treatment effects [version 2; peer review: 1 approved, 2 approved with reservations] F1000Research 2019, 8:5 https://doi.org/10.12688/f1000research.17611.2

First published: 03 Jan 2019, 8:5 https://doi.org/10.12688/f1000research.17611.1 


\section{REVISED Amendments from Version 1}

This manuscript has been revised to incorporate the reviewers comments. In the revised version, the title has been amended, additional subheadings have been added, and some paragraphs have been rearranged to follow the clinic/trial context subdivision, and the possible causes and consequences of the nocebo effect are mentioned. Moreover, the sections on classical and operant conditioning as well as learning by observation have been extended. For more details, please see the responses to the reviewers.

\section{See referee reports}

\section{Introduction}

Nocebo is often described as placebo's evil twin, and is rarely discussed on its own. This phenomenon is under-recognised in clinical practice and clinical trials, and many patients and healthcare professionals admit that they are not aware of its existence (Berthelot et al., 2001).

The nocebo effect is defined as the adverse effects of an intervention that are not related to its pharmacological or physiological effects. In research settings, it refers to the negative effects of a placebo. In clinical or trial settings, the term is used to describe the negative effects produced by placebos or either harm or lack of efficacy of the active intervention (Benedetti et al., 2007; Hahn, 1997; Häuser et al., 2012). In this paper I will not distinguish between a nocebo effect and the nocebo response and I shall refer to all the clinical/psychological or physiological changes in a patient or a group of patients that are not related to the pharmacological or physiological effect of the treatment as the nocebo effect.

The nocebo effect is mediated through negative emotions such as stress, fear, and anxiety (Aslaksen \& Lyby, 2015; Benedetti et al., 2006; Bingel et al., 2011) At the physiological level, it is associated with activation of the hypothalamic-pituitaryadrenal (HPA) axis, which controls reactions to stress, and with higher concentrations of the "stress hormone", cortisol (Benedetti et al., 2006; Johansen et al., 2003). Both the nocebo effect and HPA hyperactivity are reduced by anxiolytic drugs (Benedetti et al., 2006). Anticipatory anxiety facilitates pain transmission, at least partly through cholecystokinin receptors (Benedetti et al., 1995; Lovick, 2008) and causes nocebo hyperalgesia (Bingel et al., 2011; Keltner et al., 2006). The nocebo effect is also associated with reduced activation of dopaminergic and opioidergic systems (Scott et al., 2008; Svedman et al., 2005).

\section{Nocebo effect in clinical practice}

The consequences of the nocebo effect in clinical practice are always undesirable. It may make therapeutic interventions more painful, reduce responses to treatment, worsen symptoms or lead to adverse events, in turn causing non-adherence or discontinuation of treatment (Blasini et al., 2017). For example, an injection of an epidural analgesic can be made more painful when patients are warned that it would feel like a bee sting rather than told only that it would create a numbing sensation (Varelmann et al., 2010). Similarly, using the word "pain" rather than "a cool sensation" in a description of a procedure may make this procedure painful (Lang et al., 2005). Also, the efficacy of pharmacologically active substances was greatly reduced when they were given with contradictory information, for example bronchoconstrictors as reducing asthma and bronchodilators as provoking it (Luparello et al., 1970). Information that injection of a powerful opioidergic analgesic was started or stopped increased or decreased its analgesic effects, despite continued delivery of the drug (Bingel et al., 2011). In another study, pain ratings after the suggestion of hyperalgesia were higher than after the suggestion of analgesia, regardless of whether they were accompanied by an application of an analgesic cream or a placebo (Aslaksen et al., 2015).

The nocebo effect may also be responsible for worsening of symptoms or for new symptoms, which are often recorded as adverse effects related to the medication. For example, nebulised saline evoked asthma attacks in patients with asthma if it was given with information that contained an irritant, while the same saline relieved the symptoms if it was presented as an active treatment (Luparello et al., 1968). This is particularly important in the context of clinical trials, as a patient may be asked to record any unusual symptoms and the doctor, who may not know the patient's long-term clinical history, may be more likely to interpret any new symptom as an adverse effect of the medication. Adverse events caused by the nocebo effect are discussed in more detail in the section on nocebo in clinical trials.

In clinical settings, the nocebo effect can be easily evoked through verbal suggestion (Benedetti et al., 2007). These negative effects are usually created unintentionally, by the description of the treatment effects and adverse effects during a clinical consultation or during a consent process (Benedetti et al., 2007; Tobert \& Newman, 2016; Vase et al., 2011) The information does not have to be given directly, but may be written on a drug leaflet or patient information letter. The negative verbal suggestions may also come from sources without medical authority, such as other patients (Colloca et al., 2004), friends and family, or the media and the Internet (Crichton \& Petrie, 2015). For example, patients in countries where they are more likely to find websites about the adverse effects of statins are more likely to demonstrate statin intolerance (Khan et al., 2018). Such negative information may cause negative emotions and negative expectations about the outcomes of treatment (Häuser et al., 2012)

The nocebo effect may also be created non-verbally. It may result from observing doctors' body language (Häuser et al., 2012) or by observing the symptoms, adverse effects, and behaviour of other patients undergoing the treatment (Colloca \& Benedetti, 2009; Hahn, 1997; Świder \& Bąbel, 2013). Having one's treatment stopped may also cause the nocebo effect (Bingel et al., 2011; Colloca et al., 2004).

It may also result from one's bad experiences, through learning and conditioning. The nocebo effect may be caused by dissatisfaction with past treatment, for example due to lack of treatment 
efficacy or adverse effects (Kessner et al., 2013). This creates explicit negative expectations and attitudes that shape future responses (Faasse \& Petrie, 2013). For example, patients may assume that if the treatment didn't work in the past, it won't work this time, or they may believe that they do not tolerate the treatment (Tobert \& Newman, 2016). This effect may be reinforced by classical and operant conditioning, even without any conscious awareness of the reinforcement (Babel et al., 2017; Becker et al., 2008; Hölzl et al., 2005; Klosterhalfen et al., 2009) Classical conditioning may be associated with medical as well as non-medical cues (Jensen et al., 2015). For example, patients may feel nauseated after taking a strawberry-flavoured medicine if they experienced adverse effects after taking a medicine with that flavour in the past. Verbal suggestions and conditioning work synergistically, and that the magnitude of the effect is larger when it is caused by verbal suggestion and conditioning than by the verbal suggestion alone (Petersen et al., 2014). Negative information and conditioning cause negative expectations, negative attitudes towards treatment, and negative emotions (Price, 2015) (Benedetti et al., 2003). The expectations, in the context of the nocebo effect, may be understood in the classical sense, as a set of negative beliefs regarding the effect of the treatment in general (Elsenbruch et al., 2012), but also as an assumption and immediate prediction of what will happen next (Barsky \& Borus, 1999; Bingel et al., 2011) Conditioning may also happen without any explicit expectations (Babel et al., 2017; Bräscher et al., 2017)

The nocebo effect may also be caused by a negative attitude to the treatment or dissatisfaction with either the treatment or the doctor. For example, patients often distrust generic drugs and believe that they are less effective and more harmful than branded drugs (Al Ameri et al., 2011; Himmel et al., 2005). Patients who are switched to generic drugs tend not to adhere to treatment (Labiner et al., 2010) and report worse outcomes and more frequent adverse events (Häuser et al., 2012). Many doctors also think that generic drugs are of lower quality (Heikkilä et al., 2007), and unintentional cues that they give may make patients' attitudes even more negative and enhance the nocebo effect (Häuser et al., 2012). Similarly, a negative consultation may evoke the nocebo effect. Patients expect a doctor to understand and recognise their problems (validation), give it a name (diagnosis), explain how it is going to progress (prognosis), and offer treatment, usually in a form of a medication. If any of the elements of the consultation is negative, for example, if a doctor dismisses patients' complaints as being "all in their head", patients may feel that their treatment needs were not met and that their sickness was invalidated (Vangronsveld \& Linton, 2012). This makes them feel hopeless and angry (Häuser et al., 2012) and increases the nocebo effect (Barsky et al., 2002). Such a negative effect of consultation may be stronger than the positive effects of consultation (Greville-Harris \& Dieppe, 2015) and may persist for a long time (Blasini et al., 2017); although clinicians' positive suggestions may reduce the effect of these negative messages (Crichton \& Petrie, 2015).

\section{The nocebo effect in clinical trials}

In clinical trials, the nocebo effect manifests as reduced improvement or increased frequency of adverse events, in both the placebo and treatment arms. Patients' withdrawal from a trial due to these adverse events is also considered to be a nocebo effect (Barsky et al., 2002; Blasini et al., 2017; Tobert \& Newman, 2016). The nocebo effect in clinical trials is undesired and may distort the results of the trial; for example, if patients do not improve sufficiently, it may be concluded that the tested treatment is ineffective, or if patients report many adverse events, the conclusions may be that the treatment is harmful and the trial may be terminated early. Moreover, if these adverse events lead to the withdrawal of many participants, the missing data may further complicate interpretation of the results (Mitsikostas et al., 2011).

The nocebo effect is common, but, unlike the placebo effect, it is rarely discussed in the context of clinical trials, and it may not be considered when interpreting the results of a study. This phenomenon is under-recognised, and both the magnitude of the nocebo effect (Petersen et al., 2014) and the percentage of patients in clinical trials reporting adverse events as a result may be underestimated (Amanzio et al., 2009; Mitsikostas et al., 2011; Rief et al., 2006). For example, a meta-analysis of clinical trials of pharmacological treatments for neuropathic pain showed that about $52 \%$ (95\% CI: 36-68) of placebo-treated patients reported adverse events and 6.0\% (95\% CI: 4.5-8.0) withdrew from a trial owing to adverse events (Papadopoulos \& Mitsikostas, 2012).

In clinical trials, as in the clinic, the nocebo effect may be introduced by negative information about the beneficial and adverse effects of the tested treatment that are described in the information letter or during the informed consent process, and not by the pharmacological properties of the treatment (Barsky et al., 2002). This may bias trial outcomes, especially if these outcomes are based on patients' reports. For example, the frequency of reported gastrointestinal adverse events and discontinuation rates due to these adverse events in a trial of aspirin were much lower in a centre that did not include information about possible gastrointestinal bleeds than in two centres that included this information (Cairns et al., 1985; Myers et al., 1987). Moreover, about a quarter of patients taking placebo spontaneously report at least one adverse event, and this figure increases when they are actively asked about adverse effects (Barsky et al., 2002; Rosenzweig et al., 1993).

Some symptoms may be wrongly attributed to the treatment, and this is more likely in patients with negative expectations (Barsky et al., 2002). Trial participants may focus their attention on new symptoms and interpret normal physiological sensations or benign symptoms, which may usually get little attention, as adverse effects of the treatment (Barsky \& Borus, 1999; Gurwitz et al., 2003; Rosenzweig et al., 1993). Such symptoms are typically generalised and nonspecific, for example, nausea, 
headaches, fatigue, or irritability. They are not associated with any disease and commonly occur in healthy people not taking any medications (Eriksen \& Ursin, 2004). For example, 77\% of students responded that they had experienced at least one such symptom in the previous three days (Reidenberg \& Lowenthal, 1968). Moreover, some symptoms that are interpreted as adverse effects are highly prevalent in the populations for whom the drug is prescribed, for example headaches in women taking contraceptive pills (Grimes \& Schulz, 2011) or muscle problems in older patients taking statins (Tobert \& Newman, 2016). These "noise" symptoms may be misattributed to the treatment (Barsky et al., 2002; Grimes \& Schulz, 2011; Tobert \& Newman, 2016).

Not all nocebo-related negative effects events are "nonspecific" (Rief et al., 2009). Some complaints may be disease-specific, as patients may mistake symptoms of an underlying illness for adverse treatment effects (Fine \& Johnston, 1993). Many adverse events reported by patients taking placebo are typical of the treatment in the active arm (Amanzio et al., 2009; Barsky et al., 2002; Blasini et al., 2017; Rief et al., 2009). For example, in a meta-analysis of trials of anti-migraine treatments, anorexia and problems with memory, which often occur in patients taking anti-epileptic drugs, were reported only in patients in the placebo arms of trials of anti-epileptic drugs (Amanzio et al., 2009). In another study, the rates of adverse events were much higher in the placebo arms of trials of tricyclic antidepressants than in trials of selective serotonin reuptake inhibitors, which reflects the adverse effects profiles of these classes of drugs (Rief et al., 2009). These examples demonstrate that information about adverse effects of different classes of drugs causes expectations that may influence the experience of adverse events and may bias clinical trial outcomes (Rief et al., 2009).

The trial design itself may introduce the nocebo effect and undermine its results. For example, random assignment to different treatment regimens means that patients are not given a choice, which may create a nocebo effect (Bartley et al., 2016). However, blinding of patients and assessors reduces placebo and nocebo bias, because it tends to make the conditions and expectations identical in the active and placebo groups (Collins \& MacMahon, 2007). Lack of blinding in one study arm (observational/waiting list group) or all study arms (open-label trials) may distort trial results, as knowledge about the received treatment may affect the incidence of reported adverse events. For example, in a group of patients who knew they were taking atenolol and that erectile dysfunction may a possible adverse effect the incidence of this symptom was $31 \%$; in a group that was informed about the drug but not about the adverse effects, the incidence was $16 \%$, and in the group that was blinded and not told explicitly about this potential effect the incidence was only $3.1 \%$. In the patients who reported this adverse effect, sildenafil or placebo were equally effective in curing it (Silvestri et al., 2003).

Placebo control is useful not only to test whether the active treatment is more effective than placebo but also whether it is truly more harmful than placebo. Without a placebo control, all adverse events may be attributed to the active element of the treatment. For example, in a trial of statins, during the blinded and randomised phase, muscle-related symptoms were reported equally often in the active and placebo arms, but during the unblinded phase they were more frequent in patients taking statins (Ganga et al., 2014; Gupta et al., 2017; Kashani et al., 2006). Moreover, patients with well-documented statin intolerance due to muscle symptoms usually tolerate a statin under doubleblind conditions (Newman \& Tobert, 2015). If patients in the control group do not receive placebo but are only followed-up in the trial (so-called observational/waiting list) they may demonstrate deteriorating symptoms or reduced improvement in self-limiting conditions, because they know they are left without any treatment and their treatment expectations are not met. For that reason, a non-interventional arm does not represent the natural history of the disease, because there is a double bias: not only are these patients not blinded, but their treatment expectations are not met, because they are left with no treatment, which leads to the nocebo effect and either worsening of their symptoms or slower recovery.

\section{Recommendations and future directions}

Unlike improvement associated with placebo, there are no benefits related to the nocebo effect; it, therefore, has to be minimised by reducing pre-existing negative expectations or by preventing new ones (Tobert \& Newman, 2016).

Negative symptoms may not be reported if they are not prompted. It may be beneficial not to inform patients about potential adverse events that may be unrelated to the treatment or be of little clinical importance, such as mild headaches or nausea (Tobert \& Newman, 2016). However, it is crucial to warn patients about clinically important or potentially dangerous adverse effects predicted from the pharmacological properties of a drug; for example, warning patients not to drive or operate heavy machinery after medications that cause drowsiness. In clinical trials, it is also very important to record and include in the publication the exact content and phrasing of the information given to the participants, because it may have a substantial effect on the trial results. The nocebo effect can also be prevented by careful phrasing and positive framing of the information given to patients, for example by focusing on chances of improvement, survival, being symptom-free, and of not developing adverse effects (Crichton \& Petrie, 2015).

Another way to reduce the nocebo effect is to ask patients about their preconceptions and beliefs regarding a treatment or about previous experiences as they may negatively affect treatment outcomes. If patients' beliefs are negative (if, for example, they think they are intolerant of the prescribed medicine), they will be more likely to report adverse events at follow-up (Barsky et al., 2002), especially when starting new medications (Nestoriuc et al., 2010). Such patients will also be less likely to adhere to treatment (Barsky et al., 2002), and may be more likely to stop taking the medication altogether (Nestoriuc et al., 2010). After a change of medication, patients with negative beliefs tend to report even more adverse events than during therapy with the original drug (Nestoriuc et al., 2010). It is therefore important to change patients' attitudes before changing medications. Moreover, it may be worth asking patients to agree to a 
re-challenge with a drug they claim they do not tolerate (Tobert \& Newman, 2016), as having a choice is associated with better outcomes (Botti \& Iyengar, 2004). Finally, it is also important not to leave the patient without treatment, as any appropriately indicated treatment is better than staying on a waiting list (Khan et al., 2012).

\section{Conclusions}

The nocebo effect is always negative and unwanted. It can easily be evoked by a careless word or unfortunate phrasing. It can also be learned from one's own bad experiences or by observing others. It may also be caused by classical and operant conditioning, sometimes without patients being consciously aware of it.

Recognising the nocebo effect is important, because it may make a treatment look ineffective or harmful. For example, there may be no improvement or a much smaller improvement than expected, or the medication may seem to be poorly tolerated, with patients reporting many adverse events, which may lead to a change of therapy. However, patients who reported nonspecific complaints after one drug are likely to report even worse symptoms after a change of treatment.
The nocebo effect is also responsible for non-adherence to treatment and for discontinuation. When patients expect to feel worse or not to improve, they treat every negative sensation as being caused by the treatment, and so they do not take the treatment regularly or stop it altogether, which in turn results in a subtherapeutic dose of medication.

Any potential nocebo effect must, therefore, be recognised and minimised in the clinic and in clinical trials.

\section{Data availability}

No data is associated with this article.

\section{Grant information}

The author declares that no grants were involved in supporting this work.

\section{Acknowledgements}

The author is very grateful to Dr Jeffrey Aronson for his valuable comments.
Al Ameri MN, Whittaker C, Tucker A, et al:: A survey to determine the views of renal transplant patients on generic substitution in the UK. Transpl Int. 2011; 24(8): 770-779.

PubMed Abstract | Publisher Full Text

Amanzio M, Corazzini LL, Vase L, et al:: A systematic review of adverse events in placebo groups of anti-migraine clinical trials. Pain. 2009; 146(3): 261-269. PubMed Abstract | Publisher Full Text

Aslaksen PM, Lyby PS: Fear of pain potentiates nocebo hyperalgesia. J Pain Res. 2015; 8: 703-710.

PubMed Abstract | Publisher Full Text | Free Full Text

Aslaksen PM, Zwarg ML, Eilertsen HI, et al:: Opposite effects of the same drug: reversal of topical analgesia by nocebo information. Pain. 2015; 156(1): 39-46. PubMed Abstract | Publisher Full Text

Babel P, Bajcar EA, Adamczyk W, et al:: Classical conditioning without verbal suggestions elicits placebo analgesia and nocebo hyperalgesia. PLOS One. 2017; 12(7): e0181856.

PubMed Abstract | Publisher Full Text | Free Full Text

Barsky AJ, Borus JF: Functional somatic syndromes. Ann Intern Med. 1999; 130(11): 910-921.

PubMed Abstract | Publisher Full Text

Barsky AJ, Saintfort R, Rogers MP, et al.: Nonspecific medication side effects and the nocebo phenomenon. JAMA. 2002; 287(5): 622-627.

PubMed Abstract | Publisher Full Text

Bartley H, Faasse K, Horne R, et al:: You Can't Always Get What You Want: The Influence of Choice on Nocebo and Placebo Responding. Ann Behav Med. 2016; 50(3): 445-451.

PubMed Abstract | Publisher Full Text

Becker S, Kleinböhl D, Klossika I, et al:: Operant conditioning of enhanced pain sensitivity by heat-pain titration. Pain. 2008; 140(1): 104-114.

PubMed Abstract | Publisher Full Text

Benedetti F, Amanzio M, Maggi G: Potentiation of placebo analgesia by proglumide. Lancet. 1995; 346(8984): 1231

PubMed Abstract | Publisher Full Text

Benedetti F, Amanzio M, Vighetti S, et al:: The biochemical and neuroendocrine bases of the hyperalgesic nocebo effect. J Neurosci. 2006; 26(46): 12014-12022. PubMed Abstract | Publisher Full Text

Benedetti $\mathrm{F}$, Lanotte $\mathrm{M}$, Lopiano $\mathrm{L}$, et al:: When words are painful: unraveling the mechanisms of the nocebo effect. Neuroscience. 2007; 147(2): 260-71.

PubMed Abstract | Publisher Full Text
Benedetti F, Pollo A, Lopiano L, et al.: Conscious expectation and unconscious conditioning in analgesic, motor, and hormonal placebo/nocebo responses.

J Neurosci. 2003; 23(10): 4315-4323.

PubMed Abstract | Publisher Full Text

Berthelot JM, Maugars $\mathrm{Y}$, Abgrall M, et al.: Interindividual variations in beliefs about the placebo effect: A study in 300 rheumatology inpatients and 100 nurses. Joint Bone Spine. 2001; 68(1): 74-79.

Publisher Full Text

Bingel $\mathrm{U}$, Wanigasekera $\mathrm{V}$, Wiech $\mathrm{K}$, et al.: The effect of treatment expectation on drug efficacy: imaging the analgesic benefit of the opioid remifentanil. $\mathrm{Sci}$ Transl Med. 2011; 3(70): 70ra14.

PubMed Abstract | Publisher Full Text

Blasini M, Corsi N, Klinger R, et al.: Nocebo and pain: An overview of the psychoneurobiological mechanisms. Pain Rep. 2017; 2(2): pii: e585.

PubMed Abstract | Publisher Full Text | Free Full Text

Botti S, lyengar SS: The psychological pleasure and pain of choosing: when people prefer choosing at the cost of subsequent outcome satisfaction. $J$ Pers Soc Psychol. 2004; 87(3): 312-326.

PubMed Abstract | Publisher Full Text

Bräscher AK, Kleinböhl D, Hölzl R, et al:: Differential classical conditioning of the nocebo effect: Increasing heat-pain perception without verbal suggestions. Front Psychol. 2017; 8: 2163.

PubMed Abstract | Publisher Full Text | Free Full Text

Cairns JA, Gent M, Singer J, et al:: Aspirin, sulfinpyrazone, or both in unstable angina. Results of a Canadian multicenter trial. N Engl J Med. 1985; 313(22): 1369-1375.

PubMed Abstract | Publisher Full Text

Collins R, MacMahon S: Reliable assesment of the effects of treatments on mortality and major morbidity. Lancet. 2007; 357: 373-380.

Colloca L, Benedetti F: Placebo analgesia induced by social observational learning. Pain. 2009; 144(1-2): 28-34.

PubMed Abstract | Publisher Full Text

Colloca L, Lopiano L, Lanotte M, et al.: Overt versus covert treatment for pain, anxiety, and Parkinson's disease. Lancet Neurol. 2004; 3(11): 679-684. PubMed Abstract | Publisher Full Text

Crichton F, Petrie KJ: Accentuate the positive: Counteracting psychogenic responses to media health messages in the age of the Internet. J Psychosom Res. 2015; 79(3): 185-189.

PubMed Abstract | Publisher Full Text 
Elsenbruch S, Schmid J, Bäsler M, et al:: How positive and negative expectations shape the experience of visceral pain: An experimental pilot study in healthy women. Neurogastroenterol Motil. 2012; 24(10): 914-922.

PubMed Abstract | Publisher Full Text

Eriksen HR, Ursin H: Subjective health complaints, sensitization, and sustained cognitive activation (stress). J Psychosom Res. 2004; 56(4): 445-448. PubMed Abstract | Publisher Full Text

Faasse K, Petrie KJ: The nocebo effect: patient expectations and medication side effects. Postgrad Med J. 2013; 89(1055): 540-546.

PubMed Abstract | Publisher Full Text

Fine S, Johnston C: Drug and placebo side effects in methylphenidate-placebo trial for attention deficit hyperactivity disorder. Child Psychiatry Hum Dev. 1993 24(1): 25-30.

PubMed Abstract | Publisher Full Text

Ganga HV, Slim HB, Thompson PD: A systematic review of statin-induced muscle problems in clinical trials. Am Heart J. 2014; 168(1): 6-15.

PubMed Abstract | Publisher Full Text

Greville-Harris M, Dieppe P: Bad is more powerful than good: the nocebo response in medical consultations. Am J Med. 2015; 128(2): 126-129.

PubMed Abstract | Publisher Full Text

Grimes DA, Schulz KF: Nonspecific side effects of oral contraceptives: nocebo or noise? Contraception. 2011; 83(1): 5-9.

PubMed Abstract | Publisher Full Text

Gupta A, Thompson D, Whitehouse A, et al: Adverse events associated with unblinded, but not with blinded, statin therapy in the Anglo-Scandinavian Cardiac Outcomes Trial-Lipid-Lowering Arm (ASCOT-LLA): a randomised double-blind placebo-controlled trial and its non-randomised non-blind extension phase. Lancet. 2017; 389(10088): 2473-2481.

PubMed Abstract | Publisher Full Text

Gurwitz JH, Field TS, Harrold LR, et al.: Incidence and preventability of adverse drug events among older persons in the ambulatory setting. JAMA. 2003; 289(9): 1107-1116.

PubMed Abstract | Publisher Full Tex

Hahn RA: The nocebo phenomenon: concept, evidence, and implications for public health. Prev Med. 1997; 26(5 Pt 1): 607-11.

PubMed Abstract | Publisher Full Text

Häuser W, Hansen E, Enck P: Nocebo phenomena in medicine: their relevance in everyday clinical practice. Dtsch Arztebl Int. 2012; 109(26): 459-65.

PubMed Abstract | Publisher Full Text | Free Full Text

Heikkilä R, Mäntyselkä P, Hartikainen-Herranen K, et al.: Customers' and physicians' opinions of and experiences with generic substitution during the first year in Finland. Health Policy. 2007; 82(3): 366-374.

PubMed Abstract | Publisher Full Text

Himmel W, Simmenroth-Nayda A, Niebling W, et al.: What do primary care patients think about generic drugs? Int J Clin Pharmacol Ther. 2005; 43(10): 472-479. PubMed Abstract | Publisher Full Text

Hölzl R, Kleinböhl D, Huse E: Implicit operant learning of pain sensitization. Pain. 2005; 115(1-2): 12-20.

PubMed Abstract | Publisher Full Text

Jensen KB, Kaptchuk TJ, Chen X, et al.: A Neural Mechanism for Nonconscious Activation of Conditioned Placebo and Nocebo Responses. Cereb Cortex. 2015; 25(10): 3903-3910

PubMed Abstract | Publisher Full Text | Free Full Text

Johansen O, Brox J, Flaten MA: Placebo and Nocebo responses, cortisol, and circulating beta-endorphin. Psychosom Med. 2003; 65(5): 786-790.

PubMed Abstract | Publisher Full Text

Kashani A, Phillips CO, Foody JM, et al.: Risks associated with statin therapy: a systematic overview of randomized clinical trials. Circulation. 2006; 114(25): 2788-2797.

PubMed Abstract | Publisher Full Text

Keltner JR, Furst A, Fan C, et al:: Isolating the Modulatory Effect of Expectation on Pain Transmission: A Functional Magnetic Resonance Imaging Study. Jeurosci. 2006; 26(16): 4437-4443.

PubMed Abstract | Publisher Full Tex

Kessner S, Wiech K, Forkmann K, et al.: The effect of treatment history on therapeutic outcome: an experimental approach. JAMA Intern Med. 2013; 173(15): 1468-1469.

PubMed Abstract | Publisher Full Text

Khan A, Faucett J, Lichtenberg $\mathrm{P}$, et al:: A systematic review of comparative efficacy of treatments and controls for depression. PLOS One. 2012; 7(7): e41778.

PubMed Abstract | Publisher Full Text | Free Full Text

Khan S, Holbrook A, Shah BR: Does Googling lead to statin intolerance? Int $J$ Cardiol. 2018; 262: 25-27.

PubMed Abstract | Publisher Full Text

Klosterhalfen S, Kellermann S, Braun S, et al: Gender and the nocebo response following conditioning and expectancy. J Psychosom Res. 2009; 66(4): 323-328. PubMed Abstract | Publisher Full Text

Labiner DM, Paradis PE, Manjunath R, et al.: Generic antiepileptic drugs and associated medical resource utilization in the United States. Neurology. 2010; 74(20): 1566-1574

PubMed Abstract | Publisher Full Text
Lang EV, Hatsiopoulou O, Koch T, et al:: Can words hurt? Patient-provider interactions during invasive procedures. Pain. 2005; 114(1-2): 303-309. PubMed Abstract | Publisher Full Text

Lovick TA: Pro-nociceptive action of cholecystokinin in the periaqueductal grey: a role in neuropathic and anxiety-induced hyperalgesic states. Neurosci Biobehav Rev. 2008; 32(4): 852-862.

PubMed Abstract | Publisher Full Text

Luparello TJ, Leist $\mathrm{N}$, Lourie $\mathrm{CH}$, et al:: The interaction of psychologic stimuli and pharmacologic agents on airway reactivity in asthmatic subjects.

Psychosom Med. 1970; 32(5): 509-514.

PubMed Abstract | Publisher Full Text

Luparello T, Lyons HA, Bleecker ER, et al:: Influences of suggestion on airway reactivity in asthmatic subjects. Psychosom Med. 1968; 30(6): 819-825.

PubMed Abstract | Publisher Full Text

Mitsikostas DD, Mantonakis LI, Chalarakis NG: Nocebo is the enemy, not placebo. A meta-analysis of reported side effects after placebo treatment in headaches. Cephalalgia. 2011; 31(5): 550-561.

PubMed Abstract | Publisher Full Text

Myers MG, Cairns JA, Singer J: The consent form as a possible cause of side effects. Clin Pharmacol Ther. 1987; 42(3): 250-253.

PubMed Abstract | Publisher Full Text

Nestoriuc $\mathrm{Y}$, Orav JE, Liang $\mathrm{MH}$, et al: Prediction of nonspecific side effects in rheumatoid arthritis patients by beliefs about medicines. Arthritis Care Res (Hoboken). 2010; 62(2): 791-799.

PubMed Abstract | Publisher Full Text | Free Full Text

Newman CB, Tobert JA: Statin intolerance: reconciling clinical trials and clinical experience. JAMA. 2015; 313(10): 1011-1012.

PubMed Abstract | Publisher Full Text

Papadopoulos D, Mitsikostas DD: A meta-analytic approach to estimating nocebo effects in neuropathic pain trials. J Neurol. 2012; 259(3): 436-447. PubMed Abstract | Publisher Full Text

Petersen GL, Finnerup NB, Colloca L, et al.: The magnitude of nocebo effects in pain: a meta-analysis. Pain. 2014; 155(8): 1426-1434.

PubMed Abstract | Publisher Full Text | Free Full Text

Price DD: Unconscious and conscious mediation of analgesia and hyperalgesia. Proc Natl Acad Sci U S A. 2015; 112(25): 7624-7625.

PubMed Abstract | Publisher Full Text | Free Full Text

Reidenberg MM, Lowenthal DT: Adverse nondrug reactions. N Engl J Med. 1968; 279(13): 678-9

PubMed Abstract | Publisher Full Text

Rief W, Avorn J, Barsky AJ: Medication-attributed adverse effects in placebo groups: implications for assessment of adverse effects. Arch Intern Med. 2006; 166(2): $155-160$

PubMed Abstract | Publisher Full Text

Rief W, Nestoriuc $Y$, von Lilienfeld-Toal A, et al.: Differences in adverse effect reporting in placebo groups in SSRI and tricyclic antidepressant trials: a systematic review and meta-analysis. Drug Saf. 2009; 32(11): 1041-1056.

PubMed Abstract | Publisher Full Text

Rosenzweig P, Brohier S, Zipfel A: The placebo effect in healthy volunteers: influence of experimental conditions on the adverse events profile during phase I studies. Clin Pharmacol Ther. 1993; 54(5): 578-583.

PubMed Abstract | Publisher Full Text

Scott DJ, Stohler CS, Egnatuk CM, et al:: Placebo and nocebo effects are defined by opposite opioid and dopaminergic responses. Arch Gen Psychiatry. 2008 65(2): 220-31.

PubMed Abstract | Publisher Full Text

Silvestri A, Galetta P, Cerquetani E, et al:: Report of erectile dysfunction after therapy with beta-blockers is related to patient knowledge of side effects and is reversed by placebo. Eur Heart J. 2003; 24(21): 1928-1932.

PubMed Abstract | Publisher Full Tex

Svedman P, Ingvar M, Gordh T: “Anxiebo", placebo, and postoperative pain BMC Anesthesiol. 2005; 5: 1-6.

PubMed Abstract | Publisher Full Text | Free Full Text

Świder K, Babel P: The effect of the sex of a model on nocebo hyperalgesia induced by social observational learning. Pain. 2013; 154(8): 1312-7. PubMed Abstract | Publisher Full Text

Tobert JA, Newman CB: The nocebo effect in the context of statin intolerance.

J Clin Lipidol. 2016; 10(4): 739-747.

PubMed Abstract | Publisher Full Text

Vangronsveld KL, Linton SJ: The effect of validating and invalidating communication on satisfaction, pain and affect in nurses suffering from low back pain during a semi-structured interview. Eur J Pain. 2012; 16(2): 239-246. PubMed Abstract | Publisher Full Text

Varelmann D, Pancaro C, Cappiello EC, et al:: Nocebo-induced hyperalgesia during local anesthetic injection. Anesth Analg. 2010; 110(3): 868-870. PubMed Abstract | Publisher Full Text

Vase L, Nørskov KN, Petersen GL, et al.: Patients' direct experiences as central elements of placebo analgesia. Philos Trans R Soc Lond B Biol Sci. 2011; 366(1572): 1913-21.

PubMed Abstract | Publisher Full Text | Free Full Text 


\title{
Open Peer Review
}

\section{Current Peer Review Status: ? $\checkmark$}

\section{Version 2}

Reviewer Report 15 July 2019

https://doi.org/10.5256/f1000research.20301.r50055

(C) 2019 Kong J. This is an open access peer review report distributed under the terms of the Creative Commons Attribution License, which permits unrestricted use, distribution, and reproduction in any medium, provided the original work is properly cited.

\author{
Jian Kong \\ Department of Psychiatry, Massachusetts General Hospital, Harvard Medical School, Charlestown, \\ MA, USA
}

Avoiding the nocebo effect may have significant clinical implications by improving treatment effect and reducing potential side effects. In this manuscript, the author discusses basic and clinical studies on nocebo effect and concludes with recommendations on avoiding this negative effect. This is a well-written manuscript. My comments are as follows:

1. Not informing patients about negative treatment information, such as potential side effects or the possibility of no treatment response, may significantly reduce the nocebo effect. A critical issue here is how to strike a balance between telling the truth and not telling patients negative information. This can be very challenging as both law and ethics are involved. Thus, the author may also want to discuss the role of law, ethics, and culture in disclosing negative information that may produce the nocebo effect.

2. The author may want to include more brain imaging studies on nocebo and placebo effects, as well as the role of consciousness in these effects. Better understanding the brain mechanism underlying the nocebo effect and how this effect may be produced unconsciously may deepen our understanding of this important phenomenon.

\section{References}

1. Kong J, Gollub RL, Polich G, Kirsch I, et al.: A functional magnetic resonance imaging study on the neural mechanisms of hyperalgesic nocebo effect.J Neurosci. 2008; 28 (49): 13354-62 PubMed Abstract | Publisher Full Text

2. Tu Y, Park J, Ahlfors S, Khan S, et al.: A neural mechanism of direct and observational conditioning for placebo and nocebo responses. NeuroImage. 2019; 184: 954-963 Publisher Full Text

Is the topic of the review discussed comprehensively in the context of the current literature?

Partly 


\section{Are all factual statements correct and adequately supported by citations? Partly}

Is the review written in accessible language?

Yes

Are the conclusions drawn appropriate in the context of the current research literature? Partly

Competing Interests: No competing interests were disclosed.

Reviewer Expertise: Brain imaging, placebo / nocebo effect, experimental pain and chronic pain, neuromodulation, and alternative medicine

I confirm that I have read this submission and believe that I have an appropriate level of expertise to confirm that it is of an acceptable scientific standard, however I have significant reservations, as outlined above.

Author Response 15 Jul 2019

Karolina Wartolowska, University of Oxford, Oxford, UK

I would like to thank the Reviewer for the excellent suggestions which I would address in my next manuscripts. The aim of this review was to give an overview of how the nocebo effect can arise and how it may distort the results of the treatment. I agree with the Reviewer that there have been many great neuroimaging studies investigating the neurobiological mechanisms underlying the nocebo. Several of these studies have been cited, including one by the Reviewer. The two publications, which have been suggested by the Reviewer and coauthored by the Reviewer, explore changes in activation and connectivity of pre-specified brain regions associated with pain processing and the nocebo response and may not be too specialised for researchers and clinicians who are not neuroscientists. I agree that the legal and cultural aspects of the nocebo effects associated with the information given by healthcare professionals are very important, but they are beyond the scope of this paper.

Competing Interests: No competing interests.

Reviewer Report 12 March 2019

https://doi.org/10.5256/f1000research.20301.r45544

(C) 2019 Bąbel P. This is an open access peer review report distributed under the terms of the Creative Commons Attribution License, which permits unrestricted use, distribution, and reproduction in any medium, provided the original work is properly cited.

Przemysław Bąbel 
Pain Research Group, Institute of Psychology, Jagiellonian University, Kraków, Poland

The paper has been revised according to my comments. Although I still think that the role of classical conditioning and observational learning should be acknowledged in the recommendations and conclusions sections of the paper, I believe that the Author has reasons not to do it.

Is the topic of the review discussed comprehensively in the context of the current literature?

Partly

Are all factual statements correct and adequately supported by citations? Partly

Is the review written in accessible language?

Partly

Are the conclusions drawn appropriate in the context of the current research literature? Partly

Competing Interests: No competing interests were disclosed.

Reviewer Expertise: Pain, memory of pain, placebo and nocebo effects, learning mechanisms of pain and placebo effects

I confirm that I have read this submission and believe that I have an appropriate level of expertise to confirm that it is of an acceptable scientific standard.

\section{Version 1}

Reviewer Report 04 February 2019

https://doi.org/10.5256/f1000research.19256.r42494

(C) 2019 Bąbel P. This is an open access peer review report distributed under the terms of the Creative Commons Attribution License, which permits unrestricted use, distribution, and reproduction in any medium, provided the original work is properly cited.

\section{Przemysław Bąbel}

Pain Research Group, Institute of Psychology, Jagiellonian University, Kraków, Poland

This is a well-written short summary of the studies on a very important issue which deserves much more attention than it actually gets. I have only two major concerns. First, the paper is focused mainly on verbal information as a source of the nocebo. Although I do agree that it is the most common source of the nocebo effect in clinical practice and clinical trials, two other sources are 
also important and their role should be discussed, i.e. previous experience (classical conditioning) and observation of other patients/participants of clinical trials (see for example 1). Especially, the role of those two additional sources should be included in the recommendations and conclusions sections of the paper.

Second, through the paper the nocebo effect is discussed mainly in terms of negative expectations, however, it is only one of the explanatory mechanisms of the nocebo effect. Although nocebo effects induced by verbal information and observational learning are usually mediated by expectations, there is growing evidence that the nocebo effect induced by classical conditioning may not always be mediated by expectations (see references $2-8$ ). Thus, I would rather avoid discussing the nocebo effect as the result of sole negative expectancies as well as I would avoid defining it in terms of negative expectations.

\section{References}

1. Benedetti F: Responding to nocebos through observation: social contagion of negative emotions.Pain. 2013; 154 (8): 1165 PubMed Abstract | Publisher Full Text

2. Bräscher AK, Kleinböhl D, Hölzl R, Becker S: Differential Classical Conditioning of the Nocebo Effect: Increasing Heat-Pain Perception without Verbal Suggestions.Front Psychol. 2017; 8: 2163 PubMed Abstract | Publisher Full Text

3. Bąbel P, Bajcar EA, Adamczyk W, Kicman P, et al.: Classical conditioning without verbal suggestions elicits placebo analgesia and nocebo hyperalgesia.PLoS One. 2017; 12 (7): e0181856 PubMed Abstract | Publisher Full Text

4. Egorova N, Park J, Kong J: In the face of pain: The choice of visual cues in pain conditioning matters.Eur J Pain. 21 (7): 1243-1251 PubMed Abstract | Publisher Full Text

5. Egorova N, Park J, Orr SP, Kirsch I, et al.: Not seeing or feeling is still believing: conscious and non-conscious pain modulation after direct and observational learning.Sci Rep. 2015; 5: 16809 PubMed Abstract | Publisher Full Text

6. Jensen KB, Kaptchuk TJ, Chen X, Kirsch I, et al.: A Neural Mechanism for Nonconscious Activation of Conditioned Placebo and Nocebo Responses.Cereb Cortex. 2015; 25 (10): 3903-10 PubMed Abstract | Publisher Full Text

7. Jensen KB, Kaptchuk TJ, Kirsch I, Raicek J, et al.: Nonconscious activation of placebo and nocebo pain responses.Proc Natl Acad Sci U S A. 2012; 109 (39): 15959-64 PubMed Abstract | Publisher Full Text

8. Jensen K, Kirsch I, Odmalm S, Kaptchuk TJ, et al.: Classical conditioning of analgesic and hyperalgesic pain responses without conscious awareness.Proc Natl Acad Sci U S A. 2015; 112 (25): 7863-7 PubMed Abstract | Publisher Full Text

Is the topic of the review discussed comprehensively in the context of the current literature?

Yes

Are all factual statements correct and adequately supported by citations? Partly

Is the review written in accessible language?

Yes

Are the conclusions drawn appropriate in the context of the current research literature? 
Partly

Competing Interests: No competing interests were disclosed.

Reviewer Expertise: Pain, memory of pain, placebo and nocebo effects, learning mechanisms of pain and placebo effects

\section{I confirm that I have read this submission and believe that I have an appropriate level of expertise to confirm that it is of an acceptable scientific standard, however I have significant reservations, as outlined above.}

Author Response 07 Mar 2019

Karolina Wartolowska, University of Oxford, UK

I would like to thank the Reviewer for a very constructive review. I agree with the Reviewer that the nocebo effect should not be defined only in terms of negative expectations regarding a treatment, especially, if the expectations are defined, in the narrow sense, as a set of beliefs about the treatment. However, the literature on nocebo uses the term "expectations" in a broader sense, being the negative state (conscious or subconscious) accompanying a treatment/therapeutic intervention. It comprises negative beliefs about treatment efficacy, negative emotions such as stress and anxiety, and anticipation and expectation of failure, lack of improvement or adverse effects. This state may be caused by previous bad experiences (either as a failed treatment or experimental classical conditioning), knowledge gained through experiences or information about treatment obtained from doctors, drug leaflets, media, other patients, by observing other patients or by learning from family and peers. As suggested by the Reviewer, the importance of classical conditioning and learning by observing others have been highlighted in the revised version of the manuscript.

Competing Interests: No competing interests were disclosed.

Reviewer Report 30 January 2019

https://doi.org/10.5256/f1000research.19256.r43476

(C) 2019 Dieppe P. This is an open access peer review report distributed under the terms of the Creative Commons Attribution License, which permits unrestricted use, distribution, and reproduction in any medium, provided the original work is properly cited.

\section{Paul Dieppe}

University of Exeter, Exeter, UK

This is a useful review of a subject that, as the author says, deserves more attention than it gets. One of my concerns is that the abstract and opening sentences state that nocebo is a result of negative expectation, and yet, as mentioned later this is only one of a number of theories as to 
how the nocebo effect may be activated. Others include invalidation (mentioned briefly), conditioning (mentioned briefly) and activation of the fight or flight response (not mentioned at all).

Another issue for me is the contexts in which nocebo can be an issue. This article mentions clinical trials, experimental settings such as pain perception, and clinical practice. I would find it easier to navigate the article if there was a clearer differentiation between these very different contexts, perhaps with subheadings.

In relation to clinical practice, the article does not mention the fact that a consultation can make a patient's disease or symptoms worse as a result of nocebo mechanisms.

In the context of clinical trials I think that more attention should be given to the fact that the consent procedure can make symptoms worse, as well as resulting in a reduced response or adverse events.

I found the English a little clumsy in places.

Is the topic of the review discussed comprehensively in the context of the current literature?

Partly

Are all factual statements correct and adequately supported by citations? Yes

Is the review written in accessible language?

Partly

Are the conclusions drawn appropriate in the context of the current research literature? Yes

Competing Interests: No competing interests were disclosed.

Reviewer Expertise: Placebo, nocebo, wellbeing and healing research

I confirm that I have read this submission and believe that I have an appropriate level of expertise to confirm that it is of an acceptable scientific standard, however I have significant reservations, as outlined above.

Author Response 07 Mar 2019

Karolina Wartolowska, University of Oxford, UK

I would like to thank the Reviewer for their useful comments. I fully agree that expectations are only one of the mechanisms responsible for nocebo effect, but they are the one that is mentioned most frequently in the literature. Other mechanisms that may cause the nocebo effect, including stress or the "fight or flight" response, have also been discussed in this 
manuscript.

I am grateful to the Reviewer for their comment on the lack of clarity regarding the subdivision of nocebo effect in clinical and trial contexts. In the revised version, additional subheadings have been added, and some paragraphs have been rearranged to follow the clinical/trial context subdivision followed by the possible causes and consequences of the nocebo effect. Hopefully, the new version of the manuscript is less clumsy and sufficiently highlights the role of conditioning, stress, consultation, and consent procedure in generating the nocebo effect.

Competing Interests: I have no competing interests.

The benefits of publishing with F1000Research:

- Your article is published within days, with no editorial bias

- You can publish traditional articles, null/negative results, case reports, data notes and more

- The peer review process is transparent and collaborative

- Your article is indexed in PubMed after passing peer review

- Dedicated customer support at every stage

For pre-submission enquiries, contact research@f1000.com 